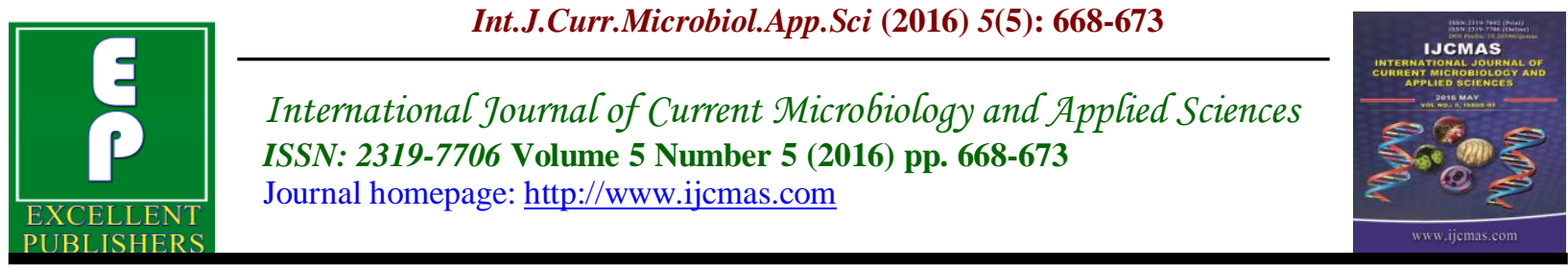

Original Research Article

http://dx.doi.org/10.20546/ijcmas.2016.505.067

\title{
Laboratory Evaluation of Chitin Synthesis Inhibitor Lufenuron in Individuals Mortality of Subterannean Termite Microcerotermes diversus (Silv.) (Isoptera : Termitidae) at Different Temperatures
}

\author{
Rahdi F. Al-Jassany* \\ Plant Protection Department, College of Agriculture, Baghdad University, Iraq \\ *Corresponding author
}

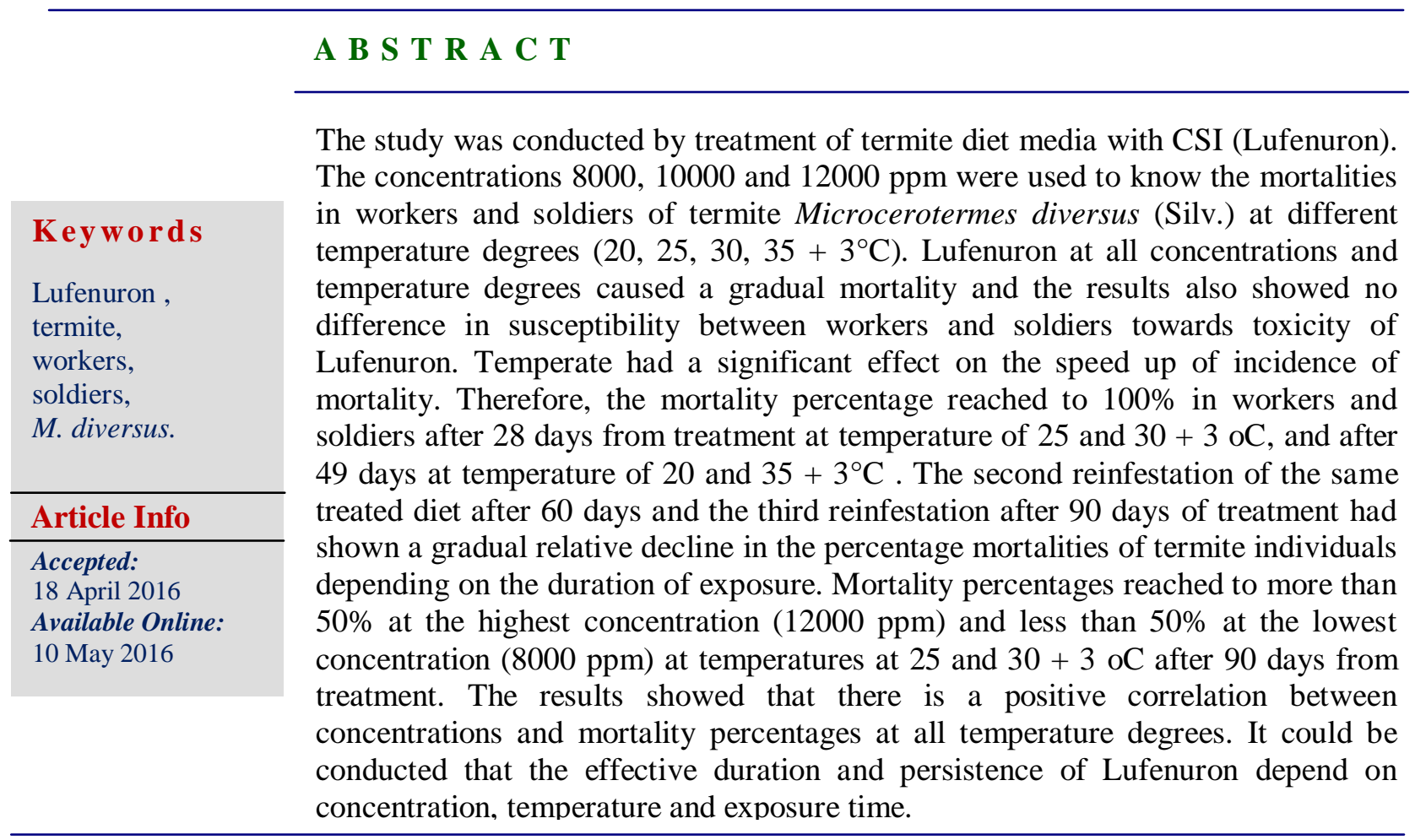

\section{Introduction}

The termite species Microcerotermes diversus (Silv.) is the most important economic pest in Iraq which damage severely the wooden structures and living trees (Al-Jassany, 1996). Different approaches have been used to control this pest. Among the newest and most effective method is the use of low-toxicity baits containing insect Growth Regulators
(Shabeen, 1997), IGRs are promising candidates for bait control of termites because of their gradual and accumulative mode of actions (Harverty et al., 1989; Su and Schffrahn, 1989).

A literature review by Rojas and Morales Ramos (2004) showed that termite feeding on foods treated with Lufenuron caused mortality percentage reached to $100 \%$ after 
eight months of treatment, while Lelis and Everaets (2004) mentioned that termite workers fed on pine wood treated with Lufenuron (25 and 200 ppm concentrations) caused a decrease in numbers of workers due to its toxic action. The insect growth regulators have different levels of acute toxicity which appeared with slow and late actions (Su and Scheffrahn, 1996 b).

The objective of this research is to evaluate the different concentrations of chitin synthesis inhibitor Lufenuron on mortality in individuals of termite $M$. diversus (Silv.).

\section{Materials and Methods}

Technical grade Lufenuron (Match 50 Ec, Syngenta Company) with concentrations of 8000, 10000 and 12000 ppm were used in this study. Wood sawdust (Partical size of 0.01 mesh) was prepared from eucalyptus trees (Eucalyptus camaldylensis) and dried in oven $\left(120^{\circ} \mathrm{C}\right)$ for $48 \mathrm{hrs}$. period $(\mathrm{Su}$, 2002). The termite media was prepared from $5 \mathrm{gm}$ of wood sawdust and $10 \mathrm{ml}$ of $4 \%$ agar solution (0.4 gm agar / $10 \mathrm{ml}$ distilled water) poured into sterilized Petri dish $(10 \mathrm{~cm}$ diameter) and left until the media was hardened (Su and Schaffrahm, 1996 a,b). 20 $\mathrm{ml}$ of each concentration were added to each perti dish (3 replicates) and left for 2 hours until complete penetration of each concentration into the media. The individuals of termite (adult workers and soldiers) were collected from a heavy infested eucalyptus trees and transferred to the laboratory for the purpose of adaptation after isolation from the colonies. To each Petri dish of 60 Petri dishes of media, adults of 50 workers and 50 soldiers were transferred. The Petri dishes were divided into 4 groups (15 Petri dish / group). Each group was transferred to an incubator at temperatures at 20, 25, 30 and $35+3$ oC with $85+5 \%$ R.H. and in total darkness. All
Petri dish were examined daily and the number of dead individuals in each treatment and its replicates were recorded until the death of all individuals. To know the residual effect of the used concentrations of Lufenuron in the above treatment in which $100 \%$ mortality was achieved, a new infestation was conducted by transfer 50 workers and 50 soldiers to each Petri dish. The number of dead individuals over a three months period was recorded monthly. The mortality percentages were corrected according to Abbott formula (Abbott, 1925).

Statically Analysis was conducted due to CRD design with ANOVA table and mean differences between treatments were compared using LSD 50\% with using SAS statical program (SAS, 2001).

\section{Results and Discussion}

The results showed that CSI (Lufenuron) is highly effective and causing mortality of termite workers and soldiers at all used concentrations and different temperature degrees $\left(20,25,30\right.$, and $\left.35+3^{\circ} \mathrm{C}\right)$. The results of the study proved that the soldiers and workers are similar in susceptibility to all treatments. The efficacy of CSI is characterized by it's a gradual causing of mortality to all treated individuals of termite in comparison to instant killing of Termicide (Chlorpyrifos). The efficacy of Lufenuron was related to temperature used in each treatment that all concentrations achieved $100 \%$ mortality in termite individuals after 28 days at temperatures of 25 and $30+3{ }^{\circ} \mathrm{C}$ (Table 2 and 3 ) and after 49 days at temperatures of 20 and $35+3^{\circ} \mathrm{C}$ (Table 1 and 3 ) in the first infestation treatment. In the second infestation treatment which conducted after 60 days of treatment of termite media the results showed a decrease in efficacy of Lufenuron along with the pass of treatment exposure time and that means a 
positive correlation between different concentrations and mortality percentages.

The highest mortality percentage achieved when temperature degrees were 25 and $30+$ $3^{\circ} \mathrm{C}$ (Table 2 and 3 ) while the least was at temperatures at 20 and $35+3{ }^{\circ} \mathrm{C}$ (Table 1 and 4).

In the third infestation of treated media which was conducted 90 days after treatment was characterized by a continuous decline in efficacy at all used concentrations of Lufenuron. The results showed that the concentration $12000 \mathrm{ppm}$ was superior in a achieving more than $50 \%$ mortality at temperature of 25 and $30+3^{\circ} \mathrm{C}$ (Table 2 and 3 ), while it was less than $50 \%$ mortality at 20 and $35+3{ }^{\circ} \mathrm{C}$ (Table 1 and 4) and the mortality percentages were statistically different at all used concentrations and temperature degrees.

Table.1 Corrected Mortality Percentages of Termite Individuals (Workers and Soldiers) in Different Lufenuron Concentrations Under $20+3^{\circ} \mathrm{C}$.

\begin{tabular}{|c|c|c|c|c|c|c|}
\hline \multirow{2}{*}{ Treatment } & \multicolumn{7}{|c|}{ Mortality after (days) } \\
\cline { 2 - 7 } & 3 & 14 & 28 & 49 & 60 & 90 \\
\hline \multirow{2}{*}{8000 ppm Luf. } & 12.66 & 36.42 & 67.94 & 100 & 9.53 & 17.28 \\
& $(15.64)$ & $(36.42)$ & 67.40 & $(100)$ & $(11.49)$ & $(17.90)$ \\
\hline \multirow{2}{*}{10000 ppm Luf. } & 20.66 & 49.28 & 82.43 & 100 & 15.89 & 34.58 \\
& $(19.04)$ & $(47.85)$ & $(78.51)$ & $(100)$ & $(17.76)$ & $(35.81)$ \\
\hline \multirow{2}{*}{12000 ppm Luf. } & 21.33 & 56.42 & 93.13 & 100 & 27.21 & 46.61 \\
& $(19.72)$ & $(55.71)$ & $(93.33)$ & $(100)$ & $(29.61)$ & $(47.01)$ \\
\hline Chlorpyriphos 2\% & 100 & - & - & - & 100 & 100 \\
\hline LSD 5\% & 2.09 & 1.18 & 3.20 & 1.01 & 2.24 & 2.15 \\
\hline
\end{tabular}

(-) mortality percentage of soldiers

Table.2 Corrected Mortality Percentages of Termite Individuals in Different Lufenuron Concentrations Under $25+3^{\circ} \mathrm{C}$.

\begin{tabular}{|c|c|c|c|c|c|c|}
\hline \multirow{2}{*}{ Treatment } & \multicolumn{7}{|c|}{ Mortality after (days) } \\
\cline { 2 - 7 } & 3 & 14 & 28 & 49 & 60 & 90 \\
\hline \multirow{2}{*}{8000 ppm Luf. } & 5.33 & 48.94 & 100 & - & 71.73 & 52.05 \\
& $(8.66)$ & $(52.08)$ & $(100)$ & - & $(72.79)$ & $(52.05)$ \\
\hline \multirow{2}{*}{10000 ppm Luf. } & 12.0 & 58.62 & 100 & - & 79.70 & 60.88 \\
& $(14.66)$ & $(61.80)$ & $(100)$ & - & $(79.40)$ & $(60.73)$ \\
\hline \multirow{2}{*}{12000 ppm Luf. } & 16.0 & 72.41 & 100 & - & 88.40 & 76.02 \\
& $(18.0)$ & $(76.35)$ & $(100)$ & - & $(88.23)$ & $(78.26)$ \\
\hline \multirow{2}{*}{ Chlorpyriphos 2\% } & 100 & - & - & - & 100 & 100 \\
& $(100)$ & - & $-100)$ & $(100)$ \\
\hline LSD 5\% & 1.50 & 2.25 & 1.40 & - & 1.76 & 3.78 \\
\hline
\end{tabular}

(-) mortality percentage of soldiers 
Table.3 Corrected Mortality Percentages of Termite Individuals in Different Lufenuron Concentrations Under $30+3^{\circ} \mathrm{C}$.

\begin{tabular}{|c|c|c|c|c|c|c|}
\hline \multirow{2}{*}{ Treatment } & \multicolumn{7}{|c|}{ Mortality after (days) } \\
\cline { 2 - 7 } & 3 & 14 & 28 & 49 & 60 & 90 \\
\hline \multirow{2}{*}{8000 ppm Luf. } & 16.66 & 66.88 & 100 & - & 77.94 & 52.05 \\
& $(19.33)$ & $(66.66)$ & $(100)$ & - & $(77.27)$ & $(52.05)$ \\
\hline \multirow{2}{*}{10000 ppm Luf. } & 28.66 & 77.70 & 100 & - & 79.70 & 60.88 \\
& $(29.33)$ & $(79.22)$ & $(100)$ & - & $(79.40)$ & $(60.73)$ \\
\hline \multirow{2}{*}{12000 ppm Luf. } & 39.33 & 97.97 & 100 & - & 100 & 76.02 \\
& $(42.66)$ & $(99.31)$ & $(100)$ & - & $(100)$ & $(78.26)$ \\
\hline \multirow{2}{*}{ Chlorpyriphos 2\% } & 100 & - & - & - & 100 & 100 \\
& $(100)$ & - & - & - & $(100)$ & $(100)$ \\
\hline LSD 5\% & 1.82 & 2.52 & 0.76 & & 1.45 & 2.97 \\
\hline
\end{tabular}

(-) mortality percentage of soldiers

Table.4 Corrected Mortality Percentages of Termite Individuals in Different Lufenuron Concentrations Under $35+3^{\circ} \mathrm{C}$.

\begin{tabular}{|c|c|c|c|c|c|c|}
\hline \multirow{2}{*}{ Treatment } & \multicolumn{7}{|c|}{ Mortality after (days) } \\
\cline { 2 - 7 } & 3 & 14 & 28 & 49 & 60 & 90 \\
\hline \multirow{2}{*}{8000 ppm Luf. } & 36.0 & 55.16 & 76.08 & 100 & 28.37 & 24.71 \\
& $(36.0)$ & $(53.09)$ & $(74.10)$ & $(100)$ & $(27.69)$ & $(25.28)$ \\
\hline \multirow{2}{*}{10000 ppm Luf. } & 44.0 & 64.13 & 92.76 & 100 & 44.05 & 36.12 \\
& $(43.33)$ & $(61.37)$ & $(87.76)$ & $(100)$ & $(43.07)$ & $(33.85)$ \\
\hline \multirow{2}{*}{12000 ppm Luf. } & 58.66 & 80.68 & 100 & - & 61.67 & 54.37 \\
& $(58.66)$ & $(79.31)$ & $(100)$ & - & $(59.99)$ & $(53.20)$ \\
\hline \multirow{2}{*}{ Chlorpyriphos 2\% } & 100 & - & - & - & 100 & 100 \\
& $(100)$ & - & - & - & $(100)$ & $(100)$ \\
\hline LSD 5\% & 2.33 & 2.43 & 2.72 & 0.64 & 2.19 & 2.47 \\
\hline
\end{tabular}

(-) mortality percentage of soldiers

The results of this research revealed a gradual effects of Lufenuron in causing mortality of termite individuals which could due to its toxicity and physiological effects, such as its effect on chitin synthesis as well as molting. Su and et al., (1995), Lenz and et al., (1996) mentioned that addition of active ingredient of growth regulators lead to slow impact and effectiveness. Lelis and Everaets (2004) showed that feeding of workers termite Microtermes on pine wood plate treated with Lefenuron caused $100 \%$ mortality after 3 weeks.
The optimum efficacy of Lufenuron when temperature was between 25 and $30^{\circ} \mathrm{C}$, this range of temperatures is considered appropriate for activity and feeding for termite workers and lead to speed up the entrance of Lufenuron through feeding and movement into termite individuals bodies and cause toxic and physiological effects in shorter period compared with not appropriate temperatures (20 and $35+3^{\circ} \mathrm{C}$ ). Results also agreed with Van den Meracker and et al., (2002) who found that the efficiency of IGR decline dramatically when 
temperature drop to less than $20^{\circ} \mathrm{C}$ which caused an increase in stadia between moultings then delay the incidence of mortality. Delaplane and et al., (1991) showed that the temperature affected the workers feeding and moulting rate and the efficacy of baits treated with IGR increased along with an increase in temperature but decreased in low temperature.

The persistency effect of high concentration of Lufenuron in killing of termite individual for longer time in comparison to low concentrations could due to faster dissipation of low concentrations under the effect of different temperatures. The variation in effectiveness of IGR on mortality percentages to termite individuals could due to several factors which include susceptibility of termite individuals and physiological status as well as the origin of colony, exposure time, growth regulator concentration and method of reception of IGR by termite individuals (Jonson and Lenz, 1996; Su and et al., 1985; Su and Scheffrahn, 1990). On the other hands, Daiker (2011) found that burying of food baits treated with Diflubenzuron with concentration $250 \mathrm{ppm}$ laid to disappearance of termite of Reticulitermes flavipes after 91-358 days.

It could be concluded of the use of chitin synthesis inhibitor (Lufenuron) in termite bait stations as a safe method in termite control.

\section{References}

Abbot, W.S. 1925. A method of computing the effectiveness of an insecticide. $J$. Econ. Entomol., 18 : 265-267.

Al-Jassany, R.F. 1996. Evaluation of some physical measures and chlorofit $48 \%$ TC (Chlorrpyrifos) in protection building against infestation termite
Microcerotertems diversus (Silv.). $\mathrm{Ph}$. D. thesis, College of Agriculture, University of Baghdad.

Daiker, D.H. 2011. Evaluation of Diflubenzuron bait in the prevention of termite infestation new construction. Florida Department of Agriculture and Consumer Services. Pp. 10.

Delaplane, K.S., A.M., Saxton, La Fage, J.P. 1991. Foraging phenology of the Formosan subterranean termite (Isoptera : Rhinotermitidae) in Louisiana. American Midland Naturalist, 125: 222-230.

Harverty, M.I., N.Y. Su, M., Tamashiro, Yamamoto, R. 1989. Concentration dependent presoldier induction and feeding deterrency potential of two insect growth regulators for remedial control of the Formosan subterranean termite (Isoptera : Rhinotermitidae). J. Econ. Entomol., 82: 1370-1374.

Jones, S.C., Lenz, M. 1996. Fenoxycarb induced caste differentiation and mortality in Coptotermus formosanus. J. Econ. Entomol., 83(3) : 875-878.

Lelis, A.T., Evaraets, C. 2004. Effects of Juvenile hormone analogues on Reticulitermes santonensis workers. J. Morphol., 228 : 1523-1542.

Lenz, M., P.V. Gleeson, R.L. Miller, Abby, H.M. 1996. How predictive are laboratory experiments for assessing the effects of chitin synthesis inhibitor (CSI) on field colonies of termite. A comparison of laboratory and field data from Australian mound building species of termite. Paper prepared for the 27th Annual meting Guadeloupe, France. No. I.R.G / WPab. Pp. 1-12.

Rojas, M.G., Morales - Rameos, J.A. 2004. Disruption of reproductive activity of Coptotermes formosanus (Isoptera: Rhinotermitidae) primary 
reproductive by three chitin synthesis inhibitors. J. Econ. Entomol., 97(6): 2015-2020.

SAS Institute Inc. 2001. SAS / Stat Guide for personal computer. Version 6 ed. SAS Institute, Cary, N.C.USA.

Shabeen, L. 1997. So, what about termite baits, are they all they're cracked up to be ? Pest control, 43-48.

Su, N.Y., Scheffrahn, R.H. 1989. Comparative effect of an insect growth regulator, S-31183 against the Formosan subterranean termites and East subterranean termites (Isoptera: Rhinotermitidae). J. Econ. Entomol., $82: 1125-1129$.

Su, N.Y., Scheffrahn, R.H. 1990. Potential of insect growth regulators as a termicide. A review Sociobiol., 17: 313-328.

Su, N.Y., Scheffrahn, R.H. 1996a. A review of the evolution criteria for bait toxicant efficacy against field colonies of subterranean termite (Isoptera). Sociobiol., 28: 521-530.

Su, N.Y., Scheffrahn, R.H. 1996b. Comparative effects of two chitin synthesis inhibitors, Hexaflumuron and Lufenuron in bait matrix against subterranean termite (Isoptera: Rhinotermitidae). J. Econ. Entomol., 89: 1156-1160.

Su, N.Y., M. Tamashiro, Harvety, M.I. 1985. Effects of three insects growth regulators feeding substrates and colony origin on survival and presoldier production of the Formosan subterranean termite. J. Econ. Entomol., 78 : 1259-1263.

Su, N.Y., E.M. Thomas, P.M. Ban, Scheffrahn, R.H. 1995. A monitoring /baiting station to detect and eliminate foraging population of subterranean termite near structures. J. Econ. Entomol., 88 : 932-936.

Van den Meiracker, K.G., P.A. Zungoli, E.P. Benson, Bridges, W.C. 2002. Hexaflumuron induced mortality in Reticulitermes flavipes and Coptotermes formosanus at constant and fluctuating temperatures (Isoptera : Rhinotermitidae). Biol. Control, 30: 523-529.

\section{How to cite this article:}

Rahdi F. Al-Jassany. 2016. Laboratory Evaluation of Chitin Synthesis Inhibitor Lufenuron in Individuals Mortality of Subterannean Termite Microcerotermes diversus (Silv.) (Isoptera : Termitidae) at Different Temperatures. Int.J.Curr.Microbiol.App.Sci.5(5): 668-673. doi: http://dx.doi.org/10.20546/ijcmas.2016.505.067 